\title{
ANÁLISE DA SUSTENTABILIDADE EMPRESARIAL: UM ESTUDO ENVOLVENDO UMA INDÚSTRIA MINERADORA
}

\author{
ANALYSIS OF BUSINESS SUSTAINABILITY: A STUDY INVOLVING A MINING INDUSTRY
}

Lucien Max Pereira *

Mestre em Administração pela Universidade Federal da Paraíba.

João Pessoa, PB, Brasil

E-mail: lucian.pereira@yahoo.com.br

\section{RESUMO}

A sustentabilidade empresarial faz parte da pauta de debates que envolvem questões ambientais, econômicas e sociais. Neste sentido, o presente estudo tem como proposta analisar a sustentabilidade a partir de um modelo de mensuração empresarial que toma como referência a perspectiva teórica do Triple Bottom Line (3BL). O modelo adotado para o desenvolvimento desta pesquisa foi o Grid de Sustentabilidade Empresarial (GSE). O objeto de estudo trata-se de uma exploração sobre a sustentabilidade empresarial de uma mineradora brasileira a partir de um modelo de mensuração de sustentabilidade. Investigou-se o conjunto de práticas adotadas pela empresa a fim de se mensurar a sustentabilidade nas dimensões ambiental, econômica e social. Para o processo de coleta de dados foi utilizado um questionário estruturado composto por questões envolvendo 43 indicadores de sustentabilidade, sendo 16 ambientais, 14 econômicos e 13 sociais. A mineradora apresentou desempenho satisfatório no que tange a sustentabilidade nas dimensões consideradas. Entre as ações de destaque indicadas pela mineradora, encontram-se: políticas de reflorestamento, recuperação do solo, utilização de tecnologias limpas, interação satisfatória com a sociedade, benefícios e políticas de valorização dos funcionários, investimentos limpos e estratégias de conciliação entre responsabilidade socioambiental e desempenho econômico.

Palavras-chave: Mensuração da sustentabilidade empresarial. Mineração brasileira. Perspectiva Triple Bottom Line. Grid de Sustentabilidade Empresarial.

\section{ABSTRACT}

The corporate sustainability currently is part in the agenda of environmental, economic and social debates. In this sense, the present study aimed to analyze the sustainability from a measurement model that takes as reference the theoretical perspective of the Triple Bottom Line (3BL). The model adopted for this research was the Corporate Sustainability Grid (CGS). The object of study it is an exploration of corporate sustainability in a Brazilian mining company from a measurement model of sustainable performance. We investigated the practices adopted by the company in order to measure sustainability in environmental, economic and social dimensions. A questionnaire consisting of 43 questions sustainability indicators, 16 environmental, 14 economic and 13 social, was used for data collection. The mining showed satisfactory performance with respect to sustainability dimensions studied, and illustrated as a case of good economic, environmental and social performance. Among the outstanding shares of the mining company are: political reforestation, land reclamation, use of clean technologies, satisfactory interaction with society, and political benefits of recovering staff, clean and investment strategies for reconciling environmental responsibility and good economic performance.

Keywords: Corporate sustainability measurement. Brazilian mining. Triple Bottom Line perspective. Corporate Sustainability Grid.

Data de aprovação: 7 de março de 2016.

Data de submissão: 30 de novembro de 2013. 


\section{INTRODUÇÃO}

A discussão sobre práticas empresariais, principalmente as que estão associadas ao equilíbrio de desempenho empresarial, tem ganhado força desde o advento da Conferência das Nações Unidas sobre o Meio Ambiente e o Desenvolvimento (CNUMAD), ocorrida em 1992. Apesar de ter muitas controvérsias sobre o debate centrado na indústria, posicionamento político dos países e poucos avanços nos acordos firmados à época (MERCADO; CÓRDOVA, 2005), o tema vem se sustentado em meio acadêmico, empresarial, político e sociedade como um todo. Como reflexo do debate sobre o desenvolvimento econômico em equilíbrio com questões naturais (ambientais) e sociais, a sustentabilidade ganha espaço como um mantra do Século 21 (DYLLICK; HOCKERTS, 2002).

Em termos mais práticos, a discussão do desenvolvimento sustentável envolve conceitos que refletem debates multidisciplinares sobre desenvolvimento econômico e empresarial, questões de responsabilidade social, reputação corporativa, economia global, criação de valor para acionistas, geração de empregos, preservação de ecossistemas, uso eficiente e ecologicamente correto de recursos naturais, preservação do patrimônio cultural entre outros (DYLLICK; HOCKERTS, 2002; BARATA, 2007; CLARO et al, 2008).

Desta forma, a mensuração do desenvolvimento sustentável de empresas ganha importância (AZAPAGIC; PERDAN, 2000).O debate tem grande relevância à medida que os acionistas, sociedade e empresas se deparam com a realidade das práticas empresariais até o presente momento, sobretudo considerando-se a relevância das ações e políticas sustentáveis para que se garanta o futuro das próximas gerações (DYLLICK; HOCKERTS, 2002; GIBSON, 2012).

A temática parece ganhar relevância ao levantar pontos sobre a identificação de corporações sustentáveis e insustentáveis. A partir desta perspectiva, fatores controláveis e não controláveis são alvos em estudos que levantam a sustentabilidade como um ponto essencial que envolve a necessidade de identificação, mensuração e avaliação de estratégias que digam respeito ao desenvolvimento empresarial sustentável (EPSTEIN; ROY, 2001) e a problemática da avaliação da sustentabilidade na indústria como um todo (AZAPAGIC; PERDAN, 2000).

O desenvolvimento de empresas sustentáveis, portanto, é intrínseco à busca pelo conhecimento de quão sustentáveis as empresas vêm agindo e trabalhando segundo uma determinada ótica. É nesse sentido que o modelo quantitativo a ser aplicado, desenvolvido por Callado e Fensterseifer (2011), se insere no debate como uma proposta para avaliar a sustentabilidade empresarial em um determinado contexto industrial.

Partindo do pressuposto de que as dimensões econômica, social e ambiental são necessárias para avaliação do nível de sustentabilidade empresarial, o modelo, denominado Grid de Sustentabilidade Empresarial (GSE) é adotado para mensurar a sustentabilidade empresarial de uma mineradora brasileira. A partir da integração de escores que refletem os índices de sustentabilidade em um total de 43 indicadores, nas dimensões econômica, social e ambiental (CALLADO; FENSTERSEIFER, 2011), ponderados por pesos definidos com o auxílio de 10 especialistas, o modelo fornece insumos, com bases quantitativas, para análise da sustentabilidade empresarial.

Uma vez que o tema sustentabilidade norteia, hodiernamente, debates gerenciais a respeito do desempenho empresarial, a presente pesquisa se propõe aplicar o Modelo GSE para mensurar o desempenho sustentável de uma empresa de mineração localizada no Brasil. A indústria foi selecionada com 
base na importância da atividade de mineração (estando o Brasil entre os maiores produtores de minério) e práticas relacionadas à sustentabilidade, no âmbito da mineração e utilização de recursos naturais e áreas para as atividades inerentes à produção mineral.

Um panorama da indústria, a partir de estudos do International Council of Mining \& Metals, ICMM, (2012), demonstra que a indústria, além de produtora de trilhões de dólares anualmente, opera com constante busca à sustentabilidade empresarial, estando o Brasil entre os grandes produtores de minérios a nível global e inserido na discussão do desenvolvimento de atividades de mineração sustentável. Em termos numéricos, por exemplo, de acordo com o ICMM (2012), a indústria brasileira responde por cerca de $3 \%$ a $4 \%$ do Produto Interno Bruto nacional ao mesmo tempo em que representa cerca de $20 \%$ do volume financeiro de exportações no país.

$\mathrm{Na}$ presente pesquisa a sustentabilidade empresarial é percebida através do comportamento da empresa em relação às ações e programas desenvolvidos, ora mensurados a partir da perspectiva do Triple Bottom Line (3BL). Destaca-se, nesse sentido, que a linha de pesquisa ora discutida é, portanto, a sustentabilidade no contexto empresarial. A pesquisa, dessa forma, parte do pressuposto de que a importância das discussões sobre a sustentabilidade ganhou força no meio acadêmico, inclusive nos estudos relacionados às organizações.

O problema da pesquisa, por sua vez, se estrutura em torno de como uma mineradora é definida em termos de sustentabilidade a partir da aplicação de um modelo de mensuração (o Grid de Sustentabilidade Empresarial/GSE). A questão norteadora da pesquisa é: Qual é o desempenho sustentável apresentado por uma mineradora brasileira a partir do Modelo Grid de Sustentabilidade Empresarial? O objetivo geral da pesquisa é aplicar o GSE através de um estudo de caso de uma empresa de grande porte com projeção nacional e internacional. De maneira complementar, o presente trabalho teve como proposta investigar as ações e políticas empresariais nas dimensões econômica, social e ambiental.

A coleta de dados foi realizada a partir de um questionário contendo um total de 52 questões e foi aplicado a dois gestores (gerente-geral da unidade visitada e o coordenador-geral de gestão ambiental e saúde no trabalho), que responderam, conjuntamente, pelas informações passadas a respeito de questões gerais e específicas da empresa. A análise dos dados, por sua vez, foi realizada com base nos escores e dimensões do GSE, conforme pressupostos do modelo adotado e métodos de obtenção dos resultados descritos no trabalho de Callado e Fensterseifer (2011). Ao final da pesquisa, conforme atual praxe científica, foram elencadas algumas limitações inerentes à problemática e ao caso estudado, além de propostas de estudos posteriores. 


\section{REVISÃO DA LITERATURA}

A discussão da sustentabilidade empresarial ergue-se em pilares que, de acordo com Claro et al. (2008), estão associados às dificuldades e problemas relacionados a práticas, políticas e instrumentos gerenciais capazes de operacionalizar e gerar resultados no âmbito dos conceitos de sustentabilidade empresarial.

Neste sentido, junto aos objetivos da pesquisa, divide-se a revisão em 4 importantes tópicos: (1) discussão do desenvolvimento sustentável e a sustentabilidade empresarial; (2) dimensões da sustentabilidade a partir da perspectiva adotada (Triple Bottom Line/3BL); (3) conceitos inerentes aos indicadores de sustentabilidade e mensuração a partir de modelos quantitativos; e (4) principais pressupostos do modelo (Grid de Sustentabilidade Empresarial - GSE).

\section{Desenvolvimento sustentável e sustentabilidade empresarial}

O foco da discussão sobre sustentabilidade geralmente apresenta aos debatedores e interessados no tema dimensões para serem analisadas. Inicialmente, deve-se aceitar alguma definição de sustentabilidade. Esta, conforme Dyllick e Hockerts (2002) refere-se à capacidade que as organizações têm de satisfazer os interesses de stakeholders diretos e indiretos sem comprometer a habilidade de satisfazer as necessidades de futuros stakeholders.

Outro conceito que pode ser considerado mais abrangente que o anterior, é o adotado por Lumley e Armstrong (2004, p. 2): "[...] desenvolvimento que satisfaz as necessidades presentes sem comprometer a capacidade das gerações futuras satisfazerem suas próprias necessidades".

Tendo como marco a conceituação inicial, a sustentabilidade é definida, para fins desta pesquisa, a partir de uma perspectiva empresarial, sem, contudo, buscar esgotar a discussão teórica sobre desenvolvimento sustentável em seus vários prismas.

Barata (2007) explica que no âmbito do desenvolvimento sustentável, o papel empresarial mantémse em posição central, como um ator essencial ao seu alcance pleno. $\mathrm{O}$ empresariado brasileiro, neste contexto, vem enfrentando grandes desafios para conciliar interesses econômicos com mudanças conjunturais que fomentam ainda mais a necessidade de se atingir o desenvolvimento sustentável.

O estudo do desenvolvimento sustentável levanta a necessidade de, a partir de algumas definições, se elencarem os capitais que alguns autores definem como essenciais para o entendimento da sustentabilidade: capital econômico, natural e social.

De acordo com Shrivastava e Hart (1995, p. 155), a sustentabilidade tem elevada importância quando colocado em pauta o uso dos recursos naturais que a sociedade necessita para manter-se em pleno desenvolvimento, sem que este desenvolvimento comprometa as gerações futuras. Os mesmos autores dissertam que:

O conceito de desenvolvimento sustentável oferece uma maneira de reconciliar os objetivos econômicos e ambientais [...]. Desenvolvimento sustentável é baseado atividades econômicas que reconhecem a finitude e a natureza vulnerável dos recursos da Terra e a necessidade de usá-los prudentemente. 
Todavia, a dimensão natural é apenas um dos prismas para se considerar a sustentabilidade. E, no contexto empresarial, tal discussão também é pautada por elementos de eficiência e efetividade nas dimensões social e econômica (DYLLICK; HOCKERTS, 2002).

Desta forma, em consonância com Dyllick e Hockerts (2002); Shrivastava e Hart (1995) e Barata (2007), pode-se visualizar a sustentabilidade como uma questão de grande interesse da sociedade como um todo, quando se levanta a problemática do cumprimento dos objetivos econômicos e sociais, sem, contudo, deixar de se considerar a importância do uso eficiente dos recursos naturais. A capacidade, portanto, de suprir as gerações atuais e futuras e o papel empresarial são pontos de destaque quando se estuda o desenvolvimento sustentável.

\section{Dimensões da sustentabilidade: Breves apontamentos sobre a perspectiva Triple Bottom Line (3BL)}

Conforme Claro et al. (2008), embora os conceitos de sustentabilidade e aspectos inerentes ao tema sejam tópicos constantemente estudados no meio acadêmico, inclusive com pesquisas sobre as dimensões cultural e tecnológica, classicamente os trabalhos trazem as dimensões econômica, social e ambiental como elementos chave do debate.

De acordo com Norman e MacDonald (2004), a perspectiva do Triple Bottom Line, ou 3BL, é um paradigma para o sucesso empresarial desde que se reconheceu que obrigações ético-sociais e ambientais permeiam os interesses dos stakeholders.

Muitos estudos têm se baseado na perspectiva 3BL, além de se reconhecer que as empresas têm projetado indicadores e gerido seus recursos de forma a contemplar essa perspectiva (KRAJNC; GLAVIC, 2005).

De acordo com Munasinghe (1997), os estudos sobre sustentabilidade a partir das dimensões ambiental, econômica e social, partem, inicialmente, da dimensão ambiental, que de acordo com Claro et al. (2008) foca na ciência ambiental, ecologia, diversidade, qualidade do ar e da água, saúde humana e habilidade de administrar os recursos naturais. A segunda dimensão, a econômica, em linhas gerais, concentra-se no sistema econômico, micro e macro, local, nacional e internacional. Por fim, a dimensão social traz à tona questões como a qualidade de vida no trabalho, o respeito aos direitos humanos, a remuneração justa, a política social e a valorização do capital humano (CLARO et al, 2008).

Com base nos conceitos de Claro et al (2008); Munasinghe (1997); MacDonald (2004) e Krajnc e Glavic (2005), pôde-se perceber a importância da perspectiva Triple Bottom Line quando se levantam tópicos de análise da sustentabilidade. Esta, por vezes, é analisada a partir das dimensões ambiental, econômica e social.

Seja considerando-se desde a administração eficiente dos recursos naturais, a saúde e qualidade de vida humana, a manutenção do sistema econômico, a melhoria do desempenho empresarial e a atenção às necessidades da sociedade. A perspectiva Triple Bottom Line faz-se presente como uma abordagem consistente com os objetivos de avaliações do desempenho sustentável de empresas. 


\section{Indicadores de sustentabilidade e mensuração a partir de modelos}

Um número cada dia crescente de empresas tem adotado ações em torno da identificação dos direcionadores do desempenho empresarial. Neste âmbito, as empresas têm evoluído bastante em relação à resposta aos interesses dos stakeholders (GIBSON, 2012) e o desenvolvimento de ações e estratégias que traduzam, de forma pragmática, as responsabilidades da empresa com a sociedade (EPSTEIN; ROY, 2001).

De acordo com Azapagic e Perdan (2000), não se pode ignorar a quantificação necessária aos conceitos de sustentabilidade, pois tais conceitos, para serem traduzidos em ações e estratégias, exigem que os tomadores de decisão mensurem indicadores. Desta forma, permitindo a padronização (standardization) dos relatórios e informações sobre o desempenho sustentável, quando alinhado à perspectiva adotada, uma empresa vem sendo (AZAPAGIC, 2004).

Segundo Veleva e Ellenbecker (2001), bons indicadores tendem a ser possíveis de se utilizar em qualquer organização, são fáceis de entender e operacionalizar e, de forma bastante clara, devem ser padronizados e servirem de apoio à tomada de decisão estratégica nas organizações.

Callado e Fensterseifer (2011) levantam algumas premissas dos indicadores a partir de revisões teóricas, entre eles: (1) relevância; (2) clareza no delineamento, (3) qualidade; (4) baixo custo, (5) melhoria contínua, (6) viabilidade, (7) objetivos e fundamentos bem estabelecidos e (8) comunicação da informação.

Segundo Azapagic e Perdan (2000), um modelo geral de indicadores para a mensuração dos níveis de sustentabilidade da indústria é de suma importância para, além de permitir a comparação entre empresas diferentes em seus níveis de desenvolvimento sustentável, padronizar as propostas de ações e generalizar, teoricamente, em razão dos resultados padronizados.

\section{O modelo adotado: Grid de Sustentabilidade Empresarial (GSE)}

É crescente o número de empresas que passam a reconhecer a importância da temática da sustentabilidade para a análise do desempenho empresarial. Para melhorar o desempenho gestores têm se voltado para análise dos direcionadores de desempenho, os aspectos transmitidos aos stakeholders e as ações que podem tomar para afetar os custos e receitas decorrentes de práticas empresariais (EPSTEIN; ROY, 2001).

Assim, procedimentos e sistemas de medição são inseridos em processos de análise do desempenho empresarial. O trabalho desenvolvido por Callado e Fensterseifer (2011), neste sentido, propõe um modelo capaz de, através de escores parciais baseados em 43 indicadores - sendo 16 ambientais, 14 econômicos e 13 sociais - integrar um escore de sustentabilidade empresarial e fornecer uma localização espacial do desempenho de sustentabilidade da empresa.

Esta mesma ferramenta de análise permite ainda interpretações sobre cada um dos itens que compõe o modelo a partir de informações fornecidas pela empresa. A estrutura do modelo, visualizando-o de forma ampla, segundo as etapas de operacionalização, é constituída de cálculos conforme o escore: Primeiro, os 
cálculos dos escores parciais de sustentabilidade (EPS) são executados a partir dos 43 indicadores definidos para o modelo e pesos atribuídos por especialistas ${ }^{1}$ em sustentabilidade.

O cálculo segue conforme equação 1 :

Desempenho da Empresa $=\sum_{i=1}^{n} w_{i} p_{i}$

Onde,

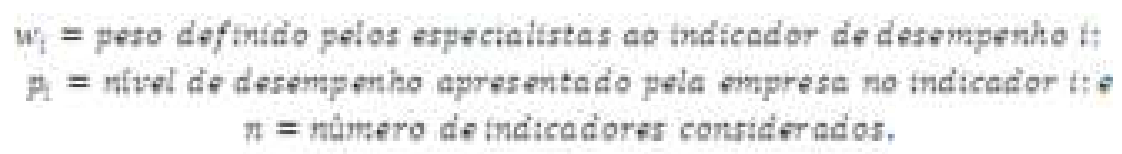

Os escores produzem, como pontos referenciais (que são intervalos de Escores Parciais de Sustentabilidade) ${ }^{2}$, escores mínimo, médio e máximo, indicando o desempenho da empresa (inferior, intermediário e superior). A partir dos escores os resultados assumirão os valores 1 e 0 , sendo 1 para as empresas que apresentarem desempenho igual ou superior ao escore médio e 0 para as empresas que apresentarem desempenho inferior ao escore médio da dimensão analisada.

A segunda etapa do modelo consiste na construção de índices agregados de sustentabilidade obtidos através do somatório de indicadores de desempenho pertencentes às diferentes dimensões de sustentabilidade ambiental. O Escore de Sustentabilidade Empresarial (ESE) consiste em somar os Escores Parciais de Sustentabilidade (EPS), nas dimensões ambiental, econômica e social. As pontuações obtidas no ESE podem ser percebidas da seguinte maneira: $\mathrm{ESE}=0$, sustentabilidade empresarial insuficiente; $\mathrm{ESE}=$ 1, sustentabilidade empresarial fraca; $E S E=2$, sustentabilidade empresarial relativa; e $E S E=3$, sustentabilidade empresarial satisfatória.

Essas informações devem servir de insumo para reflexões dos gestores e tomadores de decisão sobre o posicionamento da empresa em relação a práticas sustentáveis.

Finalmente, a terceira etapa de operacionalização do modelo consiste na integração dos escores e a produção do Grid de Sustentabilidade Empresarial. Este Grid, conforme Callado e Fensterseifer (2011):

A partir de interações entre os possíveis Escores Parciais de Sustentabilidade (EPS) e das quatro faixas de sustentabilidade empresarial resultantes dos Escores de Sustentabilidade Empresarial (ESE), são obtidos 8 (oito) posicionamentos espaciais que compõem o Grid de Sustentabilidade Empresarial (GSE).

A inserção da empresa no GSE, portanto, é inerente a dois pontos: (a) a percepção e entendimento dos Escores de Sustentabilidade Empresarial (ESE), variantes de 0 a 3, indicando, portanto, as quatro faixas de sustentabilidade do modelo; e (b) o posicionamento espacial da sustentabilidade, por sua vez descrita no Grid a partir da análise dos resultados e sua posição espacial no GSE (com possibilidades de I a VIII).

Os resultados do GSE e posicionamentos espaciais são expostos, respectivamente, conforme o Quadro 1 e a Figura 1.

\footnotetext{
${ }^{1}$ Os critérios metodológicos de atribuição dos pesos e escolha dos especialistas são apresentados no trabalho de Callado e Fensterseifer (2011).

${ }^{2}$ Conforme Callado e Fensterseifer (2011), os valores mínimo, médio e máximo, por dimensão são: (1) Ambiental: Mínimo = 35,643; Médio = 71,286; e Máximo = 106,929; (2) Econômica: Mínimo = 29,179; Médio = 58,358; e Máximo = 87,537; e (3) Social: Mínimo = 28,483; Médio = 56, 966; e Máximo = 85, 449.
} 
Quadro 1 - Composições de resultados e posicionamentos do Grid de Sustentabilidade Empresarial (GSE).

\begin{tabular}{|c|c|c|c|c|}
\hline \multicolumn{4}{|c|}{ RESULTADOS } & \multirow{2}{*}{$\begin{array}{c}\text { Posicionamento no } \\
\text { Grid de } \\
\text { Sustentabilidade } \\
\text { Empresarial (GSE) }\end{array}$} \\
\hline $\begin{array}{l}\text { Escore Parcial de } \\
\text { Sustentabilidade } \\
\text { Econômica (EPS } \mathrm{E} \text { ) }\end{array}$ & $\begin{array}{c}\text { Escore Parcial de } \\
\text { Sustentabilidade } \\
\text { Social (EPSs) }\end{array}$ & $\begin{array}{l}\text { Escore Parcial de } \\
\text { Sustentabilidade } \\
\text { Ambiental (EPS }\end{array}$ & $\begin{array}{l}\text { Escore Parcial de } \\
\text { Sustentabilidade } \\
\text { Empresarial (ESE) }\end{array}$ & \\
\hline 0 & 0 & 0 & 0 & 1 \\
\hline 0 & 0 & 1 & 1 & II \\
\hline 0 & 1 & 0 & 1 & III \\
\hline 1 & 0 & 0 & 1 & IV \\
\hline 1 & 1 & 0 & 2 & $\mathrm{~V}$ \\
\hline 0 & 1 & 1 & 2 & VI \\
\hline 1 & 0 & 1 & 2 & VII \\
\hline 1 & 1 & 1 & 3 & VIII \\
\hline
\end{tabular}

Fonte: Callado e Fensterseifer (2011).
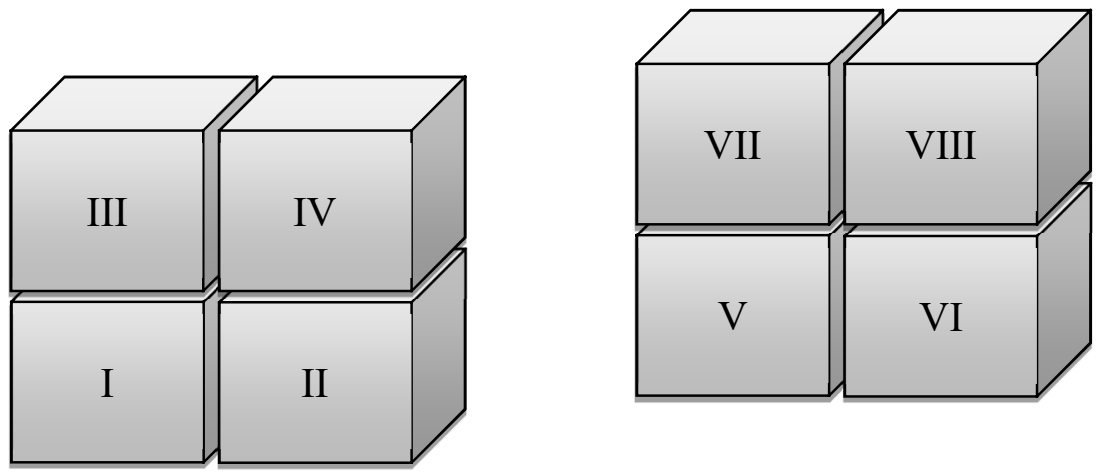

Figura 1. Grid de Sustentabilidade Empresarial e posição espacial do GSE. Adaptado de Callado e Fensterseifer (2011).

Decorre do posicionamento espacial no GSE que empresas, conforme enquadradas nas posições de I a VIII, apresentam as seguintes características, de acordo com Callado Fensterseifer (2011): (I) baixo desempenho econômico, não possuem boa interação social e não estão comprometidas com aspectos ambientais; (II) baixo desempenho econômico, boa interação social, mas não estão comprometidas com aspectos ambientais; (III) baixo desempenho econômico, não possuem boa interação social e não estão comprometidas com aspectos ambientais; (IV) bom desempenho econômico, não possuem boa interação social e não estão comprometidas com aspectos ambientais; (V) bom desempenho econômico e boa interação social, mas não estão comprometidas com aspectos ambientais; (VI) baixo desempenho econômico, mas boa interação social e comprometidas com aspectos ambientais; (VII) bom desempenho econômico, não possuem boa interação social, mas estão comprometidas com aspectos ambientais; e (VIII) bom desempenho econômico, boa interação social e comprometidas com aspectos ambientais.

A partir da integração dos Escores de Sustentabilidade Empresarial (ESE) e posterior enquadramento da empresa de acordo com os resultados de sustentabilidade, na posição espacial encontrada. A análise pertinente consegue traduzir os 43 indicadores em resultados que resumem, a partir das dimensões ambiental, econômica e social, o desempenho de sustentabilidade empresarial de uma ou mais empresas. Desta forma, o Grid de Sustentabilidade Empresarial (GSE) permite posicionar as empresas em coerência com a perspectiva 3BL e a mensuração do desempenho sustentável. 


\section{PROCEDIMENTOS METODOLÓGICOS}

A pesquisa caracteriza-se por um estudo exploratório, uma vez que se propõe a explorar um determinado aspecto pouco discutido, sobre um dado tema (SAMPIERI et al, 2006). Este, por sua vez, é a discussão da mensuração do desempenho sustentável empresarial a partir de um modelo quantitativo que agrega as dimensões ambiental, econômica e social no contexto brasileiro.

O presente trabalho, alinhado à abordagem de um estudo de caso, busca a compreensão de uma situação, de um fenômeno específico (STAKE, 2000; WISTON, 1997), no presente estudo caracterizado com a aplicação do modelo em um determinado contexto empresarial em uma única empresa. Adota-se a estratégia de estudo de caso (EISENHARDT, 1989), a fim de que um caso particular, em um contexto específico, forneça relevante embasamento teórico para a construção científica do tema, tendo também como perspectivas a possibilidade de generalizações teóricas posteriores e a partir das limitações do estudo, possibilidades de novas pesquisas.

O modelo foi escolhido com base na literatura disponível, acerca de casos brasileiros de mensuração do desempenho de sustentabilidade empresarial de forma quantitativa. A empresa não foi escolhida de forma probabilística, sendo, portanto, selecionada por conveniência (SAMPIERI et al, 2006) alinhada à estratégia do estudo de caso (STAKE, 2000; EISENHARDT, 1989; WISTON, 1997) e suas decorrências teóricas. Contudo, a eleição da empresa foi feita com base na relevância do setor de mineração para a discussão da temática sustentabilidade.

Em relação à aplicação do modelo, utiliza-se como pilar central o de Callado e Fensterseifer (2011) que tratou da elaboração e teste de um modelo voltado à mensuração da sustentabilidade empresarial no setor vinícola no Rio Grande do Sul. A replicação, na realidade deste caso, é direcionada ao contexto da mineração no Brasil.

O instrumento de coleta de dados, alinhado com o modelo supracitado (Grid de Sustentabilidade Empresarial), consiste em um questionário estruturado contendo um total de 52 questões, sendo 8 de informações da empresa (Grupo I) e 43 de indicadores presentes no modelo (Grupo II). O questionário foi aplicado a dois gestores (gerente-geral da unidade visitada e o coordenador-geral de gestão ambiental e saúde no trabalho), que responderam, conjuntamente, pelas informações passadas a respeito de questões gerais e específicas da empresa. A escolha dos respondentes do questionário foi definida com base na conveniência da alta administração da empresa. Neste sentido, ressalta-se que a Diretoria da empresa autorizou os referidos gestores a representarem a empresa no que se referiu ao presente trabalho.

A pesquisa seguiu o seguinte roteiro: (1) Análise do modelo original com o objetivo de adaptá-lo à realidade local; (2) Revisão da teoria abrangente sobre a sustentabilidade empresarial, mensuração do desempenho, dimensões da sustentabilidade e a indústria de mineração nacional e internacional; (3) Visita e aplicação do instrumento de pesquisa na empresa investigada; (4) Medição e apresentação dos resultados; e (5) discussão das conclusões, limitações e perspectivas de pesquisas. 


\section{CONTEXTUALIZAÇÃO DO SETOR E CARACTERIZAÇÃO DA EMPRESA INVESTIGADA}

A indústria de mineração enfrenta alguns dos desafios mais críticos quando se discute a sustentabilidade empresarial (AZAPAGIC, 2004). De acordo com o Instituto Brasileiro de Mineração - IBRAM (2011), a mineração no Brasil, definida como a Produção Mineral Brasileira (PMB), atingiu cerca de US\$ 50 bilhões no ano de 2011, configurando um aumento de $28 \%$ em relação ao ano de 2010.

Ainda acerca da mineração no Brasil, o IBRAM (2011) apresentou que ano de 20107932 empresas trabalhando com mineração no país, sendo 942 na região centro-oeste, 1258 na região nordeste, 439 na região norte, 3392 na região sudeste e 1901 na região sul. Do ano 2000 até 2011, de acordo com o IBRAM (2011) a produção de minérios no Brasil, em bilhões de dólares, cresceu em 550\%, além de empregar, hoje, 2,1 milhões de trabalhadores formais.

Azapagic (2004) identifica que a indústria de minérios geralmente é dividida em quatro subsetores: (1) Minérios de energia; (2) Minérios metálicos; (3) Minérios de construção; e (4) Minérios da indústria. Figuram entre os grandes produtores países como os EUA, Brasil, China, Rússia, Canadá, Austrália, União Europeia e África do Sul (AZAPAGIC, 2004). Dada a importância do setor, conforme Whitmore (2006), a sustentabilidade com vistas à mineração tem ganhado destaque junto a agendas internacionais de debate sobre o tema.

A discussão sobre a sustentabilidade de atividades de exploração de recursos naturais escassos mantém-se em consonância com o que é apresentado por Azapagic (2004), ao levantar a questão de que uma gama de stakeholders, entre eles empregados, organizações não governamentais, agências de regulamentação ambiental, acionistas, governos, empresas, autoridades e comunidades locais têm preocupações e interesses voltados a aspectos econômicos, sociais e ambientais.

A empresa alvo do presente estudo está localizada no nordeste brasileiro, atua com a extração de minérios pesados, utilizados amplamente na indústria desde tintas, componentes eletrônicos, ligas metálicas e insumos para produção de cosméticos. A empresa faz parte de um grupo internacional e fornece seus produtos para o Brasil, Argentina, Estados Unidos e Canadá. Pela definição de Azapagic (2004), a empresa se enquadra no grupo 4 , fornecendo minérios e produtos derivados à indústria.

A visita foi realizada em uma das filiais da empresa, que possui uma mina com área de aproximadamente 1000 hectares, com perspectiva de exploração até 2020. A mina visitada fornece um dos componentes básicos para que a matriz, localizada no Estado da Bahia, produza os componentes finais que são vendidos amplamente para empresas produtoras de cerâmicas, tintas, plásticos e ligas metálicas.

A empresa emprega, no Brasil, cerca de 550 funcionários, gerando uma folha de pagamento e benefícios de aproximadamente 12 milhões anuais. A partir da visualização de seu Balanço Patrimonial, em conformidade com as categorias de empresas de mineração apresentados pelo ICMM (2012) a empresa figura-se entre os exploradores juniores, que são aqueles que possuem ativos totais entre US\$ 5 milhões e US $\$ 500$ milhões e totalizam, no mundo, quase 2500 empresas.

O grupo do qual faz parte, contudo, figura-se entre os Sêniores do setor, empregando mais de 4000 funcionários e, em 2011, apresentando lucro líquido de US\$ 500 milhões. Em seu site institucional, a empresa expõe sua preocupação com a recuperação ambiental, geração de renda junto à comunidade local e informações diversas sobre as políticas de gestão e o Sistema Integrado de Gestão (SIG). 
A partir das informações supracitadas foi selecionado o caso para o desenvolvimento da presente pesquisa, que se propõe avaliar o desempenho sustentável da mineradora em questão, nas dimensões ambiental, econômica e social, tendo como referência a empresa brasileira.

\section{APRESENTAÇÃO DOS RESULTADOS}

A empresa apresentou (conforme Tabelas 1, 2 e 3), pontuação máxima em 35 dos 43 indicadores de sustentabilidade empresarial que configuram o GSE, os 8 indicadores restantes apresentaram pontuação intermediária. Tal pontuação, prévia ao escore parcial, indicou que a empresa desenvolve atividades que contemplam boa parte dos níveis de sustentabilidade nas três dimensões (ambiental, econômica e social).

Entre as ações que se destacam nas dimensões estão às certificações internacionais e nacionais de qualidade, as políticas de inclusão da comunidade local, seja em atividades de conscientização ambiental, projetos de geração de trabalho e renda e profissionalização para novas contratações (que priorizam a região, definida como o município localizado e municípios próximos).

A empresa também se atenta a questões como a utilização de uma matriz energética baseada em tecnologias limpas (eólica e biomassa), uso de biodiesel em veículos pesados, exploração mineral sem uso de agentes tóxicos ao solo e águas (processo de exploração baseado principalmente em água). Há um constante monitoramento do uso de água, com objetivo de reduzir e reutilizar as águas, inclusive havendo, em seu sistema de medição do desempenho, indicadores que contemplam ações voltadas à utilização consciente da água, energia e demais recursos da empresa.

Além destas, a empresa também tem políticas de participação dos lucros, incentivos aos estudos e benefícios para empregados e funcionários terceirizados. Outro ponto importante é o fato de a empresa monitorar os acidentes e a prevenção destes, seja ambiental ou em relação ao trabalhador.

Existe, ainda, um sistema de gestão integrado que em sua essência se baseia nas dimensões ambiental, econômica e social (dentro desse sistema, um formal sistema de gestão ambiental é consolidado em torno de ações voltadas ao reflorestamento de áreas exploradas, utilização eficiente das águas e da energia, recuperação do solo e investimentos em segurança e responsabilidade ambiental). No que tange ao desempenho econômico, a empresa consegue conciliar todas as ações anteriores com um desempenho crescente, com lucro líquido, em 2011, superior em 14,5\% em relação a 2010 , e retorno sobre o capital investido $13,2 \%$ superior a 2011. 
Tabela 1 - Escores de desempenho da empresa na dimensão ambiental

\begin{tabular}{|c|c|}
\hline INDICADORES & Pontuação \\
\hline 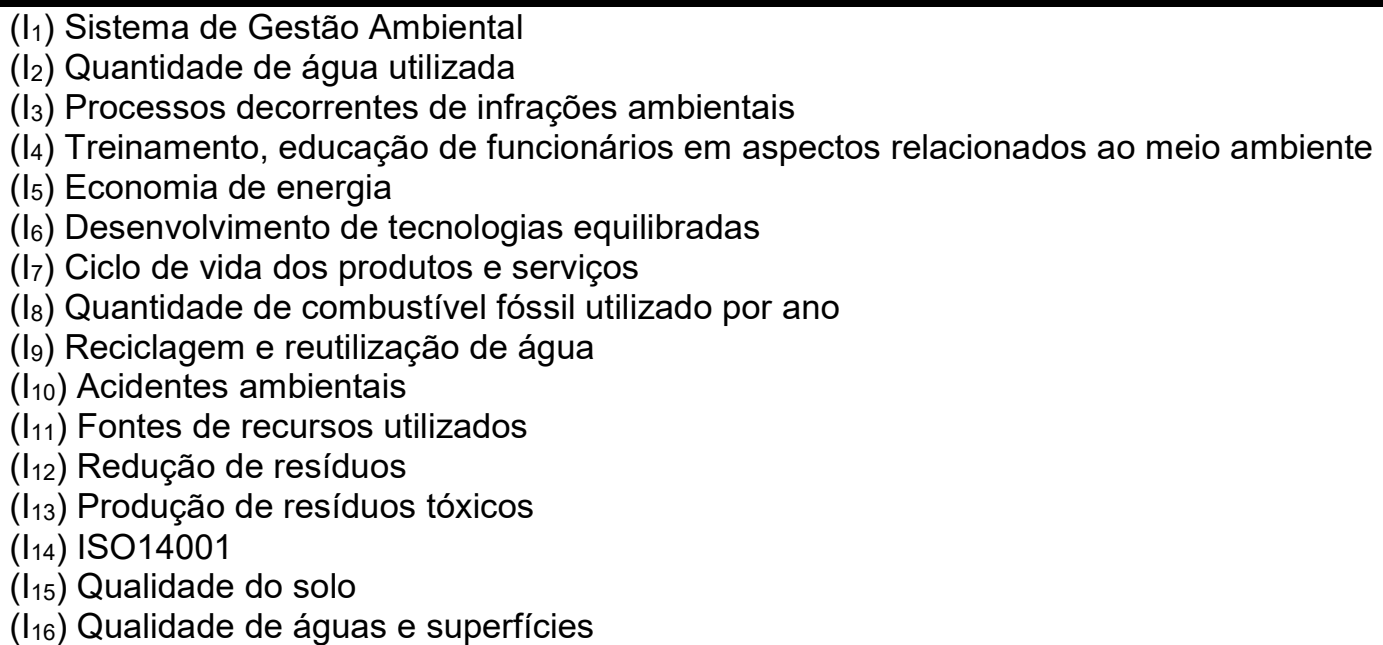 & $\begin{array}{l}3 \\
3 \\
3 \\
3 \\
3 \\
3 \\
3 \\
3 \\
3 \\
3 \\
3 \\
3 \\
3 \\
3 \\
2 \\
2\end{array}$ \\
\hline
\end{tabular}

Fonte: Pesquisa de campo, 2012.

Observação 1: $(A)$ = Dimensão ambiental; $(E)$ = Dimensão econômica; e $(S)$ = Dimensão Social.

Observação 2: Escore 1 = desempenho inferior; Escore 2 = desempenho intermediário; e Escore 3: desempenho superior.

A partir da mensuração dos indicadores de desempenho na dimensão ambiental, pôde-se perceber que a empresa apresentou desempenho intermediário apenas nos indicadores de Qualidade do Solo e Qualidade de águas e superfícies. Nos demais indicadores a empresa obteve desempenho máximo, destacando-se entre as principais políticas de gestão e responsabilidade ambiental: a reciclagem e racionalização do uso da água disponível, matriz energética limpa (eólica e biomassa), ações de prevenção e contenção de acidentes ambientais e treinamento de funcionários a fim de se alinharem às diretrizes do Sistema de Gestão Ambiental adotado pela empresa.

Os indicadores de desempenho intermediário são resultados do fato de que atividade de mineração causa dano ao solo e águas, contudo a empresa reconhece os danos e atua em razão da minimização dos efeitos e recuperação das águas e do solo atingidos.

Tabela 2 - Escores de desempenho da empresa na dimensão econômica

\begin{tabular}{|c|c|}
\hline INDICADORES & Pontuação \\
\hline $\begin{array}{l}\text { (I17) Investimentos éticos } \\
\left(I_{18}\right) \text { Gastos em saúde e em segurança } \\
\left(I_{19}\right) \text { Investimento em tecnologias limpas } \\
\left(I_{20}\right) \text { Nível de endividamento } \\
\left(I_{21}\right) \text { Lucratividade } \\
\left(I_{22}\right) \text { Participação de mercado } \\
\left(I_{23}\right) \text { Passivo ambiental } \\
\left(I_{24}\right) \text { Gastos em proteção ambiental } \\
\left(I_{25}\right) \text { Auditoria } \\
\left(I_{26}\right) \text { Avaliação de resultados da organização } \\
\left(I_{27}\right) \text { Volume de vendas } \\
\left(I_{28}\right) \text { Gastos com saúde e demais benefícios } \\
\left(I_{29}\right) \text { Retorno sobre o capital investido } \\
\left(I_{30}\right) \text { Selos de qualidade }\end{array}$ & $\begin{array}{l}3 \\
3 \\
3 \\
2 \\
3 \\
3 \\
2 \\
3 \\
2 \\
3 \\
2 \\
3 \\
3 \\
3\end{array}$ \\
\hline
\end{tabular}

Fonte: Pesquisa de campo, 2012.

Observação 1: $(A)$ = Dimensão ambiental; $(E)$ = Dimensão econômica; e $(S)$ = Dimensão Social.

Observação 2: Escore 1 = desempenho inferior; Escore 2 = desempenho intermediário; e Escore 3: desempenho superior 
Em relação a dimensão econômica a empresa obteve pontuação máxima em 10 dos 14 indicadores, tendo, nos demais, efetuado pontuação intermediária. Práticas de gestão como investimentos em tecnologias limpas, gastos em proteção ambiental, saúde e demais benefícios e a obtenção de selos de qualidade impulsionaram os escores. O nível de endividamento se manteve inalterado nos últimos 3 anos, o volume de vendas se manteve quase que constante, embora a empresa tenha sido mais lucrativa no mesmo período.

Tabela 3 - Escores de desempenho da empresa na dimensão social

\begin{tabular}{lc}
\hline \multicolumn{1}{c}{ INDICADORES } & Pontuação \\
\hline (I $\left.\left.\right|_{31}\right)$ Geração de trabalho e renda & 3 \\
$\left(I_{32}\right)$ Auxílio em educação e treinamento & 3 \\
$\left(I_{33}\right)$ Padrão de segurança de trabalho & 3 \\
(I34) Ética organizacional & 3 \\
$\left(I_{35}\right)$ Interação social & 3 \\
$\left(I_{36}\right)$ Empregabilidade e gerenciamento de carreira & 3 \\
$\left(I_{37}\right)$ Políticas de distribuição de lucros e resultados entre funcionários & 3 \\
$\left(I_{38}\right)$ Conduta de padrão internacional & 3 \\
$\left(I_{39}\right)$ Capacitação e desenvolvimento de funcionários & 3 \\
$\left(I_{40}\right)$ Acidentes fatais & 3 \\
$\left(I_{41}\right)$ contratos legais & 3 \\
$\left(I_{42}\right)$ Stress de trabalho & 2 \\
$\left(I_{43}\right)$ Segurança do produto & 2 \\
\hline
\end{tabular}

Fonte: Pesquisa de campo, 2012.

Observação 1: $(A)$ = Dimensão ambiental; $(E)$ = Dimensão econômica; e $(S)$ = Dimensão Social.

Observação 2: Escore 1 = desempenho inferior; Escore 2 = desempenho intermediário; e Escore 3: desempenho superior.

$\mathrm{Na}$ dimensão social apenas dois indicadores atingiram desempenho intermediário, havendo os 11 demais indicadores atingido desempenho superiores (escore 3). A empresa preza por ações que incorporam as noções de responsabilidade social junto à comunidade. Ações como auxílio à melhoria da educação de funcionários, campanhas de conscientização ambiental que fomentam a interação social, um rígido padrão de controle da segurança do trabalho e adoção de conduta de padrão internacional impulsionaram a empresa na obtenção de escores de desempenho superior na dimensão social.

Apenas os indicadores de stress de trabalho e segurança do produto atingiram desempenho intermediário, uma vez que a empresa não possui práticas constantes de redução e prevenção do stress no trabalho. Em relação à segurança do produto, apenas as informações determinadas por questões legais são mantidas nos rótulos dos produtos, não havendo mais informações complementares (adicionais aos requisitos legais exigidos).

A partir dos resultados obtidos sobre as três dimensões e os 43 indicadores avaliados, a empresa tem seu Escore de Sustentabilidade Parcial (EPS) nas dimensões ambiental, econômica e social apresentado na Tabela 4.

Tabela 4 - Escores Parciais de Sustentabilidade

\begin{tabular}{lccc}
\hline & $\begin{array}{c}\text { Dimensão } \\
\text { Ambiental }\end{array}$ & $\begin{array}{c}\text { Dimensão } \\
\text { Econômica }\end{array}$ & $\begin{array}{c}\text { Dimensão } \\
\text { Social }\end{array}$ \\
\hline Pontuação total obtida na dimensão analisada & 102,357 & 79,823 & 78,449 \\
Escore Parcial de Sustentabilidade (EPS) & 1 & 1 & 1 \\
Desempenho & Satisfatório & Satisfatório & Satisfatório \\
\hline
\end{tabular}

Fonte: Pesquisa de campo, 2012.

Observação 1: Os valores mínimo, médio e máximo, por dimensão são: (1) Ambiental: Mínimo = 35,643; Médio = 71,286; e Máximo = 106,929; (2) Econômica: Mínimo = 29,179; Médio = 58,358; e Máximo = 87,537; e (3) Social: Mínimo = 28,483; Médio = 56, 966; e Máximo = 85, 449. 
Observação 2: Desempenho insatisfatório = 0 (pontuação total inferior à pontuação média); Desempenho satisfatório = 1 (pontuação total igual ou superior à pontuação média).

Deste modo, a empresa assume a posição, no GSE, de localização VIII - com a obtenção de desempenho satisfatório nas três dimensões -, conforme mostrado na Figura 2. O resultado implica que o caso estudado se refere a uma empresa que consegue conciliar bom desempenho econômico, interação social satisfatória e engajamento em atividades comprometidas com as questões ambientais.

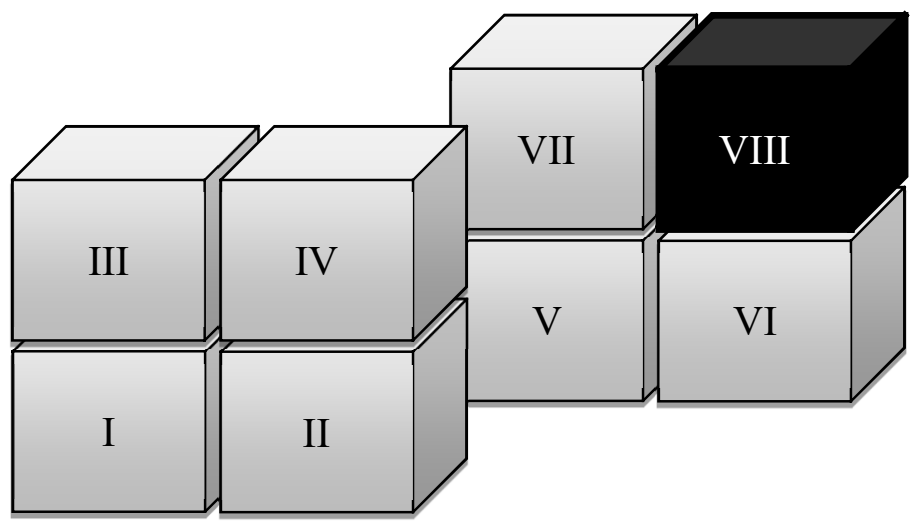

Figura 2. Posicionamento espacial da empresa no GSE a partir dos resultados da pesquisa de campo.

Fonte: Pesquisa de campo, 2012.

Tal aplicação consegue ilustrar o quanto sustentável a empresa vem sendo, no que tange às questões ambientais, econômicas e sociais (logo, contemplando o 3BL), no presente caso, atingindo, dentro das possibilidades de posição espacial de I a VIII, a localização VIII que significa que a empresa atinge um nível satisfatório de sustentabilidade nas três dimensões analisadas (ambiental = 1; econômico = 1 e social =1)

Dos 43 indicadores presentes no modelo, a empresa obteve nota máxima em 35 e nos 8 indicadores restantes, todos atingiram nível intermediário, o que indicou, sumariamente, que a empresa se posiciona de forma bastante consistente com os resultados satisfatórios, de sustentabilidade empresarial, propostos com a aplicação do modelo. 


\section{CONSIDERAÇÕES FINAIS}

A partir das possibilidades de pesquisas que envolvem a sustentabilidade, o presente trabalho se propôs analisar as dimensões consideradas pela abordagem Triple Bottom Line, ou 3BL, que utiliza como pontos de vista, para percepção da sustentabilidade empresarial, as dimensões ambiental, econômica e social.

Neste sentido, o modelo de mensuração aplicado, o Grid de Sustentabilidade Empresarial (GSE) mostrou-se bastante adequado à perspectiva adotada, além de permitir uma visualização da sustentabilidade empresarial e aplicação relativamente simples, mas consistente com a teoria fundamental que embasa a posição teórica do 3BL.

A empresa analisada, que está inserida na indústria da mineração como participante júnior (a representante nacional), simetricamente ao grupo (global), adota políticas e ações que, à primeira vista, se configuram como bastante relacionadas a ações sustentáveis, seja nos aspectos ambientais, econômicos e sociais.

A aplicação prática do modelo, no caso em questão, permitiu verificar o nível de sustentabilidade empresarial da empresa, sendo este nível foi satisfatório (com a obtenção de resultados acima da média, nas três dimensões) e possivelmente impulsionado pela série de ações e políticas que a empresa adota em sua estratégia empresarial.

A atuação no setor de mineração é sempre pautada por volumes elevados de capital investidos, escassez de recursos, vida útil (das jazidas) limitada e elevados problemas ambientais decorrentes da exploração, em alguns casos, insustentável. O presente caso apresentou como resultado final, um exemplo de satisfatório engajamento com as dimensões propostas de sustentabilidade, indicando que a atividade de mineração pode, dependendo das ações e políticas adotadas, conciliar bom desempenho econômico, adequada interação social e forte engajamento com questões ambientais.

A empresa, ao ser enquadrada na posição VIII do GSE (revelando bom engajamento social, econômico e ambiental) revelou ser um caso de mineração sustentável. Políticas de relacionamentos com a comunidade local (engajamento em ações de responsabilidade ambiental e social), matriz energética limpa, monitoramento de resultados ambientais, econômicos e sociais, investimentos limpos e desenvolvimento de tecnologias que conciliem o desenvolvimento econômico e a responsabilidade social, impulsionaram o desempenho da empresa no GSE.

Embora a pesquisa se trate de um estudo de caso, que teve como proposta analisar uma indústria de mineração acredita-se que existe como perspectiva a generalização a respeito de possibilidades de ações sustentáveis no âmbito da mineração, visto que o setor está estruturado em torno de pressões de vários stakeholders, ambiente legal bem regulamentado e limitações inerentes ao setor e as perspectivas dos investidores e sociedade como um todo.

Neste sentido, a presente pesquisa tem como uma limitação bastante visível a necessidade de se testar, empiricamente, o setor de mineração brasileiro, a fim de se verificar os níveis de sustentabilidade empresarial das principais empresas. Tal limitação serve de proposta de estudos futuros. Outra proposta, a partir das limitações do presente caso, é a revisão dos indicadores e proposição de um modelo para análise da sustentabilidade das atividades de mineração brasileira e/ou mesmo mundial, a partir da redefinição ou adaptação do presente modelo para incorporação de questões mais inerentes à atividade de mineração. 


\section{REFERÊNCIAS}

AZAPAGIC, A.; PERDAN, S. Indicators for sustainable development for industry: A General Framework. Institution of Chemical Engeneers, vol 78, Part B, July, 2000.

AZAPAGIC, A. Developing a framework for sustainable development indicators for the mining and minerals industry. Journal of Cleaner Production, vol. 12, n. 6, p. 639-662, 2004.

BARATA, M. M. de L. O setor empresarial e a sustentabilidade no Brasil. Revista Pensamento Contemporâneo em Administração. Rio de Janeiro, vol. 1, n. 1, p. 93-114, 2007.

CALLADO, A. L. C.; FENSTERSEIFER, J. E. Corporate Sustainability Measure from an Integrated Perspective: the Corporate Sustainability Grid (CSG). International Journal of Business Insights and Transformation, vol. 3, n. 3, p. 44-53, 2011.

CLARO, P. B. O.; CLARO, D. P.; AMÂNCIO, R. Entendendo o conceito de sustentabilidade nas organizações. Revista de Administração, vol.43, n.4, p.289-300, 2008

DYLLICK, T.; HOCKERTS, K. Beyond the business case for corporate sustainability. Business Strategy and Environment, vol. 11, n. 2, p. 130-141, 2002.

EISENHARDT, K.M. Building theories from case study research. Academy of Management Review, vol. 14, n. 4, p. 532$550,1989$.

EPSTEIN, M. J.; ROY, M-J. Sustainability in action: Identifying and measuring the key performance drivers. Long Range Planning, vol. 34, n. 5, p.585-604, 2001.

GIBSON, K. Stakeholders and Sustainability: An evolving theory. Journal of Business Ethics, vol. 109, n. 1, p. 15-25, 2012.

IBRAM. Instituto Brasileiro de Mineração. Informações e análises da economia mineral brasileira. 6. ed, 2011. Disponível em < http://www.ibram.org.br >. Acesso em 26 de junho de 2012.

ICMM. International Council of Mining \& Metals. InBrief: Minings contribution to sustainable development - an overview. Junho de 2012. Disponível em: < http://www.icmm.com >. Acesso em 05 de julho de 2012.

KRAJNC, D.; GLAVIC, P. How to compare companies on relevant dimensions of sustainability. Journal of Ecological Economy, vol. 55, n. 4, p. 551-563, 2005.

LUMLEY, S.; ARMSTRONG, P. Some of the nineteenth century origins of the sustainability concept. Environment, DevelopmentandSustainability, vol. 6, n. 3, p. 367-378, 2004.

MERCADO, A.; CÓRDOVA, K. Dessarolo sustentable - Industria: Más controversas menos respuestas. Ambiente e Sociedade, vol. 8, n. 1, , p.1-25, 2005.

MUNASINGHE, M. Environmental Economics and Sustainable Development. The International Bank of Reconstruction and Development/ The World Bank. Washington: The World Bank, 1997.

NORMAN, W.; MacDONALD, C. Getting to the bottom of "Triple Bottom Line". Business Ethics Quartely, vol.14, n. 2, p. 243-262, 2004.

OPPENHEIM, A.N. Questionnaire design, interviewing and attitude measurement. New York: Basic Book In, 2000.

SAMPIERI, R. H.; COLLADO, C. F.; LUCIO, B.P. Metodología de la Investigación. 4. ed. México: McGraw-Hill, 2006.

SHRIVASTAVA, P.; HART, S. Creating Sustainable Corporations. Business Strategy and the Environment, vol. 4, n. 3, p. 154-165, 1995.

STAKE, R.E. Case studies. In: DENZIN, N.K.; LINCOLN, Y.S. (Orgs.). Handbook of qualitative research. Thousand Oaks: Sage, 2000.

VELEVA, V.; ELLENBECKER, M. Indicators of sustainable production: framework and methodology. Journal of Cleaner Production, vol. 9, n. 1, p. 519-549, 2001.

WHITMORE, A. The emperor's new clothes: Sustainable mining? Journal of Cleaner Production, vol, 14, n. 3-4, p. 309314, 2006 